OPEN ACCESS

Edited by:

Maroje Sorić,

University of Zagreb, Croatia

Reviewed by:

Giuseppe Battaglia,

University of Palermo, Italy

Damir Sekulic,

University of Split, Croatia

*Correspondence:

Rubén López-Bueno

rlopezbu@unizar.es

Guillermo F. López-Sánchez gfls@um.es

Specialty section:

This article was submitted to

Children and Health,

a section of the journal

Frontiers in Pediatrics

Received: 26 June 2020

Accepted: 06 August 2020

Published: 11 September 2020

Citation:

López-Bueno R, López-Sánchez GF,

Casajús JA, Calatayud J,

Gil-Salmerón A, Grabovac I, Tully MA

and Smith L (2020) Health-Related

Behaviors Among School-Aged

Children and Adolescents During the

Spanish Covid-19 Confinement.

Front. Pediatr. 8:573.

doi: 10.3389/fped.2020.00573

\title{
Health-Related Behaviors Among School-Aged Children and Adolescents During the Spanish Covid-19 Confinement
}

\begin{abstract}
Rubén López-Bueno ${ }^{1 *}$, Guillermo F. López-Sánchez ${ }^{2 *}$, José A. Casajús ${ }^{3}$, Joaquín Calatayud ${ }^{4}$, Alejandro Gil-Salmerón ${ }^{5}$, Igor Grabovac ${ }^{6}$, Mark A. Tully ${ }^{7}$ and Lee Smith ${ }^{8}$
\end{abstract}

${ }^{1}$ Department of Physical Medicine and Nursing, University of Zaragoza, Zaragoza, Spain, ${ }^{2}$ Faculty of Sport Sciences, University of Murcia, Murcia, Spain, ${ }^{3}$ Faculty of Health Sciences, University of Zaragoza, Zaragoza, Spain, ${ }^{4}$ Exercise Intervention for Health Research Group (EXINH-RG), Department of Physiotherapy, University of Valencia, Valencia, Spain, ${ }^{5}$ Polibienestar Research Institute, University of Valencia, Valencia, Spain, ${ }^{6}$ Department of Social and Preventive Medicine, Centre for Public Health, Medical University of Vienna, Vienna, Austria, ${ }^{7}$ Institute of Mental Health Sciences, School of Health Sciences, Ulster University, Newtownabbey, United Kingdom, ${ }^{8}$ Cambridge Centre for Sport and Exercise Science, Anglia Ruskin University, Cambridge, United Kingdom

In response to the coronavirus disease 2019 (Covid-19) world pandemic, affected countries such as Spain enacted measures comprising compulsory confinement as well as restrictions regarding free movement. Such measures likely influence children's and adolescents' lifestyles. Our study aimed to investigate the impact that the Covid-19 confinement has on health-related behaviors (HRBs) among Spanish children and adolescents. An online survey was administered to 516 parents to collect data about 860 children and adolescents (49.2\% girls) aged between 3 and 16 years in relation to physical activity, screen exposure, sleep time, and fruit and vegetable consumption during the Covid-19 confinement. Respectively, $t$-paired test and $t$-test between groups served to check differences between HRBs levels before and during the confinement as well as between strict and relaxed confinement. Significant differences were found for a reduction of weekly minutes of physical activity during the confinement $(-102.5$, $S D$ 159.6) $(p<0.001)$, an increase of daily hours of screen exposure $(2.9, S D$ 2.1) $(p<0.001)$, and a reduction of daily fruit and vegetable consumption $(-0.2$, $S D$ 1.6) $(p<0.001)$. Sleep time showed a significant difference between strict and relaxed confinement $(-0.3, S D$ 0.1) $(p<0.05)$, whereas binomial logistic regression adjusted for covariates (age, sex, education of the parents, siblings, current condition, exposure to Covid-19, and previous health risk behavior) showed significantly lower odds for screen exposure risk behavior with relaxed confinement (OR 0.60, 95\% Cl 0.40-0.91). The present study suggests that Covid-19 confinement reduced physical activity levels, increased both screen exposure and sleep time, and reduced fruit and vegetable consumption. Therefore, most HRBs worsened among this sample of Spanish children and adolescents. Closure of schools, online education, and the lack of 
policies addressing the conciliation between labor and family life could have played an important role in HRBs worsening among pupils, which might be mitigated with adequate conciliation policies, parental guidance, and community support.

Keywords: children, adolescents, health-related behaviors, lifestyle habits, coronavirus disease, confinement

\section{INTRODUCTION}

The global pandemic of coronavirus disease 2019 (Covid-19) has forced many countries to enact confinement measures to reduce the spread of the virus (SARS-CoV-2). The Spanish Government declared a state of alarm followed by a compulsory set of measures including strict free movement restrictions implemented from 15 March 2020 onwards $(1,2)$. To date, these measures have been observed to be effective since new contagious have been substantially reduced, which has permitted to start with a de-escalation phase toward usual daily routine. However, the experience of a long period of confinement may have had a significant impact on those who have suffered the strictest restrictions of free movement and other potential consequences such as the problems for families derived from the lack of conciliation between labor and family life.

In this regard, the compulsory movement restriction meant the prohibition of movement of children outside households up to 6 or more weeks in a row, with no certainty about potentially damaging consequences on their health and wellbeing. Additionally, because $94.1 \%$ of the Covid-19-infected children do not present symptoms or have mild-to-moderate disease (3), affecting mainly the elderly with whom the minors share households with (4), social distancing measures were put in place across Europe to reduce the human-to-human infection; such measures included the closing of schools and high schools. Consequently, several pupils have been affected by the temporary closing of their schools and high schools and the adoption of online learning platforms instead (5).

The United Nations stated that the mitigation measures may inadvertently do more harm than good (6), and in this context, the closing of schools and high schools supposedly isolates and socially deprives many children of all ages around the world. Numerous studies have previously linked isolation to different conditions such as cardiovascular disease among children (i.e., elevated total cholesterol, elevated blood pressure, overweight, low high-density lipoprotein level, low maximum oxygen consumption, and elevated glycated hemoglobin concentration), and social deprivation has been observed to have a negative effect over social cognition and both emotional and motor developments (7-10). Therefore, since a substantial amount of children and adolescents might have been temporarily deprived of parental care, adequate healthy and sustained routines, and cognitive and physical stimuli for their age, research relating to this topic is urgently required. For instance, due to the Covid19 movement restrictions, a higher homestay would be expected, which, in turn, might increase screen exposure (11); at the same time, higher levels of screen exposure might also lead to lower levels of physical activity and, eventually, lower sleep time $(12,13)$, which along with circadian deregulation may influence
Covid-19 infection and severity (14). Furthermore, recent studies have observed a significant reduction in physical activity levels of adults during the Covid-19 confinement $(15,16)$. Moreover, such studies have found that adults experiencing higher reductions in physical activity levels or performing lower levels of physical activity during the Covid-19 pandemic have poor mental health and well-being $(17,18)$. Indeed, similar associations observing poorer mental health as a consequence of a reduction of physical activity levels due to the Covid-19 confinement might also exist for children and adolescents.

In this unprecedented situation due to Covid-19 confinement, where infection mitigation measures may have had an impact on the usual lifestyle, there are no studies yet examining how the experience of Covid-19 confinement has influenced healthrelated behaviors (HRBs) in children and adolescents. Therefore, the present study aimed to analyze the influence of confinement over HRBs in Spanish children and adolescents, which could contribute to informing future public health strategies as aimed at this specific population. Based on previous literature, we hypothesized that both strict and relaxed Covid-19 confinement would be associated with unfavorable HRBs when compared with pre-Covid-19 confinement setting. Indeed, stronger associations between strict confinement and worse HRBs are expected.

\section{METHODS}

A parent-reported questionnaire was conducted to assess associations between phases of confinement and HRBs during the Covid-19 pandemic in children and adolescents.

\section{The Survey}

A web-form link served to collect data regarding HRBs during the period 22 March to 10 May 2020 (i.e., from the 7th day of enacted national confinement in Spain up to the 15th day of relaxed confinement for children). The survey was launched on social media on 22 March 2020, together with initial information about the aim of the study. Adults residing in Spain, aged 18 years and over, having children, and currently confined due to Covid-19 were eligible to participate. Convenience sampling was used to select the participants of the study; according to server analytics, 650 adult media users covering all the Spanish regions were invited to participate. Participants were provided with an information sheet about the study aims as well as the instructions for the survey, gave informed consent to participate, and confirmed the confined status of their children. Provided data were anonymously treated in accordance with Spanish law for general data protection. At the end of the survey, participants were provided with recommendations regarding health habits. Overall, 516 parents provided data about 860 children and adolescents in relation to the following variables: 
age, gender, education of the parents, previous condition, number of siblings, phase of confinement, exposure to Covid19, physical activity, screen exposure, sleep time, and fruits and vegetable consumption.

\section{Ethics}

The study was conducted following the principles of the World Medical Declaration of Helsinki and was approved by the Ethics Committee of Research in Humans of the University of Valencia (register code 1278789). The study was reported accordingly to the Strengthening the Reporting of Observational Studies in Epidemiology statement (19).

\section{The Phase of Confinement (Exposure)}

Data from web server corresponding to the date of completing the survey served to categorize this variable into those experiencing strict confinement (i.e., those completing the questionnaire from 1 April up to 25 April) and those experiencing relaxed confinement (i.e., those completing the questionnaire from 26 April up to 10 May). These date intervals were set in accordance to the measures enacted by the Spanish Government in relation to the Covid-19 pandemic (1, 2); strict confinement did not allow any free movement of minors outside the household if not for medical reasons or, in the case of those aged 15 or over, to do the shopping or take a dog for a short walk once a day, and, in any case, keeping a compulsory social distance of $1.5 \mathrm{~m}$ from others. On the other hand, relaxed confinement permitted minors aged below 14 years to go outside once a day for no more than an hour, accompanied by an adult, in a time band from 9:00 a.m. to 9:00 p.m. and keeping a social distance of $2 \mathrm{~m}$ from others. Also, minors aged 14 years joined the group of those aged 15 years or over to be allowed to do the same from that moment. Finally, from 2 May, those aged 14 years or over were permitted to do physical activity outside the household in two specific time bands (6:00 a.m. to 10:00 a.m. and 8:00 p.m. to 11:00 p.m.), whereas the time band for those aged below 14 years was restricted to 12:00 a.m. to 7:00 p.m. for activities outside the home. Figure 1 displays an illustration of the key dates regarding this study.

\section{Health-Related Behaviors (Outcome)}

Outcome variables were estimated through a set of four questions included in the survey in relation to four HRBs (i.e., physical activity, screen exposure, sleep time, and fruit and vegetable consumption). The answers of the parents to the following single-item questions were used as proxy measures of their children's HRBs: "How many minutes of physical activity does your child usually perform weekly?" and answers ranging from "0" to "More than 720;" "How many hours is your child usually exposed to screens such as TV, cell phone, and tablet daily?", with possible answers ranging from " $0 \mathrm{~h}$ " to "more than $10 \mathrm{~h}$;" "How many hours does your child usually sleep daily?, with answers comprising from " $<5 \mathrm{~h}$ " to "more than $10 \mathrm{~h}$;" "How many pieces of fruit and vegetables do your child usually eat daily?, and possible answers ranging from " 0 " to "more than 5." These questions were asked twice to the parents; first, referred to before the confinement setting and, second, regarding the confinement setting. Single-item questions used to estimate HRBs such as physical activity have shown high reproducibility [Spearman's rank correlation coefficients $(r=0.72-0.82)]$, as well as a strong agreement when meeting physical activity guidelines (kappa $=0.63$, 95\%CI 0.54-0.72) (20). Also, the use of parents' selfreporting to estimate children's physical activity and sedentary time has shown significant positive associations when both were accelerometer-measured ( $p<0.001)(21)$.

Based on current guidelines and relevant research, a corresponding health risk behavior was defined for each HRB as follows: $<420$ weekly minutes of physical activity (physical activity); more than $2 \mathrm{~h}$ of daily screen time (screen exposure); $<9$ daily sleep hours (sleep time); and $<3$ pieces of fresh fruits and vegetables a day (fruit and vegetable consumption) (22-25). For each HRB, participants were categorized into those meeting the definition of health risk behavior and those not meeting the definition of health risk behavior.

\section{Covariates}

According to previous research (26-28), the present study also estimated age, gender, education of the parents, previous condition, number of siblings, and exposure to Covid-19. Responses of the parents regarding their children were categorized as follows: age [cutoff points for years were set according to current school stages in Spain: infants (3-5 years), primary (6-12 years), and secondary (13-16 years)]; education of the parents ("any of the parents holding a university degree" or "none of the parents holding a university degree"); current condition ("experiencing any physical or mental condition" or "not experiencing any physical or mental condition;" number of siblings ("having one or more siblings" or "not having any sibling"); and Covid-19 exposure ("infected with Covid-19 or close to an infected person" or "not exposed"). Finally, the previous health risk behavior of the children (i.e., meeting or not meeting the definition of health risk behavior before the Covid-19 confinement) was also considered.

\section{Statistical Analyses}

Statistical analyses were conducted through Stata version 16.1 (StataCorp, Texas, USA). The Kołmogorov-Smirnov test served to check normality. Differences between each HRB before and during the confinement as well as between strict and relaxed confinement were respectively assessed using paired $t$-test and $t$-test between groups. Also, the effect size for these differences was checked calculating Cohen's d. Associations between type of confinement due to Covid-19 and each HRB were assessed using binomial logistic regressions adjusted for covariates, providing adjusted odds ratios (ORs) and 95\% CIs for the whole sample. We also conducted stratified analyses to check associations concerning gender and age. Finally, propensity score with nearest-neighbor matching served to further check the differences between strict and relaxed confinement for each HRB. Participants with missing data in any study variable were discarded for the study $(n=45)$. Levels of significance were set at $p<0.05$. 


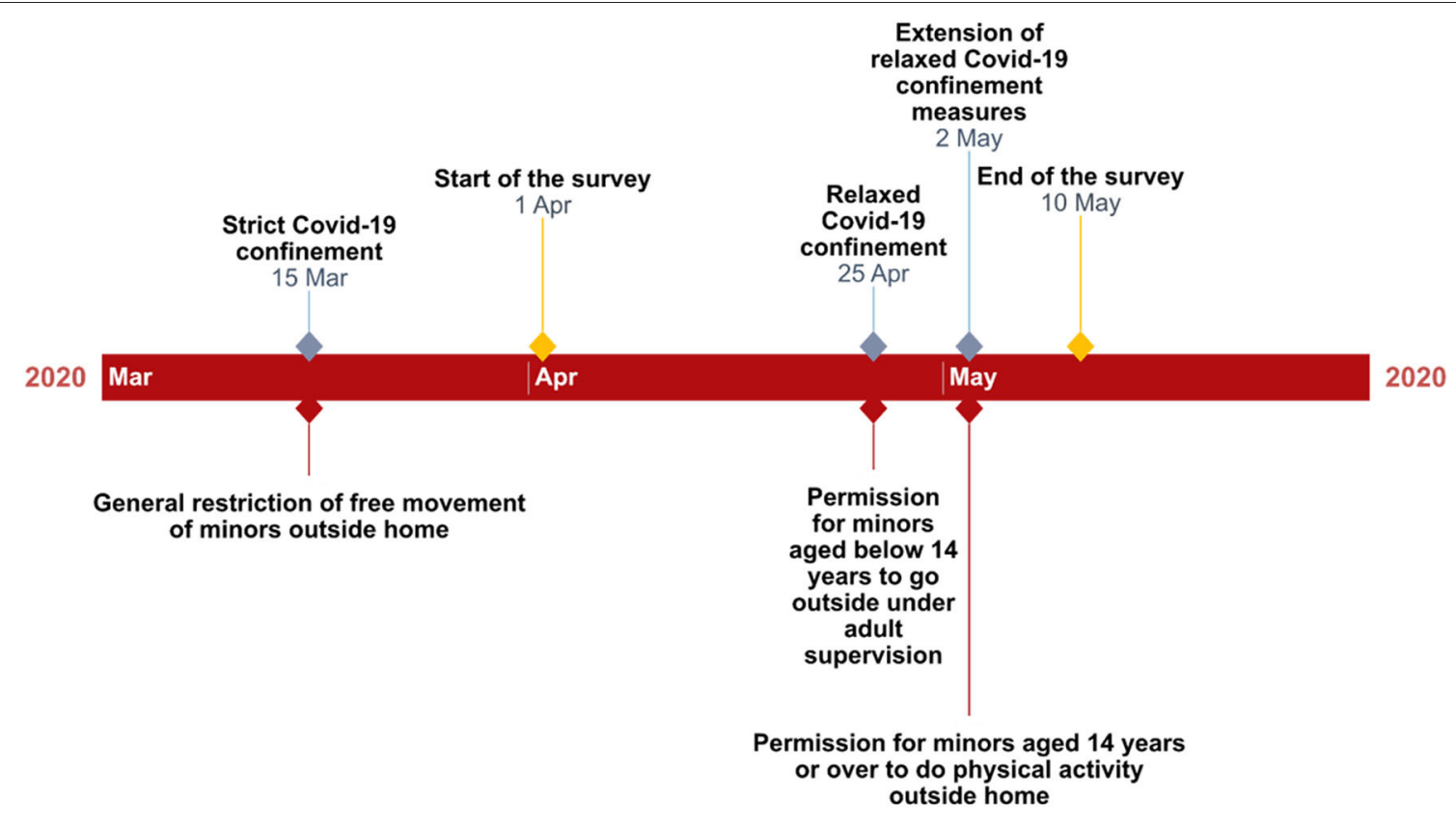

FIGURE 1 | Timeline of the most important Covid-19 confinement measures regarding minors in Spain.

\section{RESULTS}

The characteristics of the sample are presented in Table 1. A total of 860 children and adolescents on average aged 9.6 (SD 3.9) participated in this study. Of those, $423(49.2 \%)$ were girls, and $611(71.1 \%)$ were experiencing strict confinement. At the time of the questionnaire reply, 35 (4.1\%) participants declared having being exposed to Covid-19 and 144 (16.7\%) having a previous condition. Overall, the number of participants with siblings is 692 $(80.5 \%)$, whereas that with any parent holding a university degree represents $28.8 \%$ of the sample.

Table 2 shows previous levels for each HRB as well as differences between before and during Covid-19 confinement. Previous physical activity levels were estimated in 198.6 (SD 180.9) weekly minutes for the whole sample; boys and younger participants reached the highest levels with 211.9 (SD 188.4) and 223.0 (SD 198.0) weekly minutes, respectively. Screen exposure was overall estimated as 2.0 ( $S D$ 1.6) daily hours; boys 2.1 ( $S D$ 1.7) and older participants reach the highest levels 2.4 (SD 1.3) for this HRB. Concerning daily sleep hours, these are estimated in 9.1 ( $S D$ 1.2) for the entire sample; the subgroup of younger participants shows the highest values for this HRB: 9.8 ( $S D$ 1.2). Finally, daily fruit and vegetable consumption is estimated in 3.2 ( $S D$ 2.0) pieces for all the participants: boys with 3.3 ( $S D$ 2.1), and those from the younger subgroup present the highest values for this HRB with 3.7 (SD 2.1) daily pieces in subgroup comparisons. Overall physical activity and all gender and age subgroups display significant reduction between before and during the confinement; the subgroup of participants aged between 6 and 12 years displays the highest reduction of weekly minutes [-120.4 (SD 159.0)]. Also, screen exposure shows a significant increase for all the participants as well as for all subgroups; the highest increase is observed for older participants who show 3.3 (SD 2.1) more daily hours. Sleep time presents significant differences only for the younger and older participant subgroups with, respectively -0.4 (SD 1.8) and 0.6 (SD 1.7) daily hours. Concerning daily fruits and vegetable consumption, all the subgroups present significant reductions with the exception of the subgroup of older participants; the highest reductions are presented in the subgroup of the younger participants $[-0.6(S D 2.0)]$.

Table 3 shows differences concerning HRBs between strict and relaxed Covid-19 confinement. Sleep time is the only HRB that shows significant differences in both overall and specific subgroups such as boys [ $-0.4(S D$ 0.2) daily sleep hours] and participants aged between 6 and 12 years $[-0.3(S D 0.2)$ daily sleep hours].

Adjusted ORs for each health risk behavior during COVID19 confinement are presented in Table 4 . Solely screen exposure shows significant odds reduction of health risk behavior overall (OR 0.60 95\%CI 0.40-0.91) as well as in girls (OR 0.55 95\%CI $0.31-0.99$ ) and participants aged between 6 and 12 years (OR 0.26 95\%CI 0.03-0.92).

Finally, Table 5 shows the average treatment effect on treatment (relaxed confinement participants), in which none of the HRBs present significant treatment effects.

\section{DISCUSSION}

The present study provides novel data from an unprecedented set of public health measures restricting the mobility of children 
TABLE 1 | Characteristics of the study sample.

\begin{tabular}{|c|c|c|}
\hline$N=860$ & $n(\%)$ & Mean (SD) \\
\hline \multicolumn{3}{|l|}{ Gender } \\
\hline Boys & $437(50.8)$ & \\
\hline Girls & $423(49.2)$ & \\
\hline Age & & $9.6(3.9)$ \\
\hline \multicolumn{3}{|l|}{ Confinement } \\
\hline Strict & $611(71.1)$ & \\
\hline Relaxed & $249(28.9)$ & \\
\hline \multicolumn{3}{|l|}{ Education of the Parents } \\
\hline Holding a university degree & $248(28.8)$ & \\
\hline Not holding a university degree & $612(71.2)$ & \\
\hline \multicolumn{3}{|l|}{ Siblings } \\
\hline Yes & $692(80.5)$ & \\
\hline No & 168 (19.5) & \\
\hline \multicolumn{3}{|l|}{ Current Condition } \\
\hline Yes & $144(16.7)$ & \\
\hline No & $716(83.3)$ & \\
\hline \multicolumn{3}{|l|}{ Exposure to Covid-19 } \\
\hline Yes & $35(4.1)$ & \\
\hline No & $825(95.9)$ & \\
\hline \multicolumn{3}{|c|}{ Physical Activity (weekly minutes) } \\
\hline Before confinement & & $198.6(180.9)$ \\
\hline During strict confinement & & $95.5(123.8)$ \\
\hline During relaxed confinement & & $97.8(121.4)$ \\
\hline \multicolumn{3}{|l|}{ Screen Exposure (h/day) } \\
\hline Before confinement & & $2.0(1.6)$ \\
\hline During strict confinement & & $4.9(2.3)$ \\
\hline During relaxed confinement & & $4.8(2.3)$ \\
\hline \multicolumn{3}{|l|}{ Sleep Time (h/day) } \\
\hline Before confinement & & $9.1(1.2)$ \\
\hline During strict confinement & & $9.3(1.6)$ \\
\hline During relaxed confinement & & $9.0(1.7)$ \\
\hline \multicolumn{3}{|l|}{ Fruit and Vegetable } \\
\hline \multicolumn{3}{|l|}{ Consumption (portion/day) } \\
\hline Before confinement & & $3.2(2.0)$ \\
\hline During strict confinement & & $3.1(2.1)$ \\
\hline During relaxed confinement & & $2.8(1.9)$ \\
\hline
\end{tabular}

and adolescents as a result of the Covid-19 pandemic. The most relevant finding in this study with an important sample of the Spanish child and adolescent population was that overall examined HRBs, except for sleep time, worsened with the confinement. Also, only levels and odds of health risk behavior for screen exposure significantly improved during the 1 st weeks of relaxed confinement, although further analyses did not confirm such a trend. Values for physical activity, screen exposure, and fruit and vegetable consumption also worsened during the confinement in all gender and age subgroups except for $\geq 13$ and $\leq 16$ years' subgroup for the last case (i.e., fewer minutes of weekly physical activity, more hours of daily screen exposure, and less daily pieces of fruit and vegetable consumed), whereas only screen exposure improved (i.e., less time exposed to screens).

\section{Physical Activity}

The association between social isolation and lower levels of physical activity in children was reported a few decades ago (29). More recently, a reduction of physical activity (i.e., 2.30 $\mathrm{h} /$ week) has been found in prior research regarding confined children and adolescents due to Covid-19 (30); such values were higher than those found in the present study, which observed a difference of $1.40 \mathrm{~h}$ /week in respect to previous confinement levels. Differences between the two studies concerning physical activity could be attributed to different sample characteristics; for instance, children from higher socioeconomic backgrounds have shown higher levels of physical activity, whereas the context of confinement might influence physical activity levels (e.g., more time confined or experiencing stricter confinement can modify ordinary levels of physical activity) (28-32). Closure of schools during both strict and relaxed confinement might play a key role in this found reduction since schools, and, particularly physical education classes provide an adequate environment to promote active behaviors among children and adolescents (3335). Also, current research does not show evidence enough to consider the possibility that such activity behaviors could be compensated at home $(36,37)$. Finally, because healthy habits such as active commuting to schools (i.e., walking or cycling), which has been associated with increasing overall physical activity, and reducing sedentary behaviors $(38,39)$, have been restricted during both strict and relaxed confinement, it was difficult to expect that those physically active behaviors could be compensated at home; this might partially explain the finding of a recent study observing adolescents living in rural areas as more prone to reduce their physical activity levels during the Covid19 pandemic when compared with their rural counterparts (40). Particularly, adolescents with lower physical fitness were observed to greatly reduce their physical activity levels during the Covid-19 pandemic (40, 41).

\section{Screen Exposure}

With higher time spent at home, it was expected that screen exposure could reach higher levels than before the Covid-19 confinement. A recent study found screen exposure to increase by $4 \mathrm{~h}$ /day among Italian children and adolescents during Covid-19 strict confinement (30). Furthermore, online gaming and streaming activity have been observed to rise in different countries during the Covid-19 confinement (42). Also, ordinary school attendance has been largely substituted by both digital homework and digital classes in Spain, which could have added more screen time to the already existing before the confinement. Particularly, mobile phones could have had a significant impact on teenagers' socialization processes and have added more screen time while confined (43); the lower odds for health risk behavior observed for the $\geq 13$ and $\leq 16$ years' subgroups with the relaxed confinement could be also explained by higher opportunities to physically meet their friends. Moreover, since Spanish workers have been instructed to telework at home during the Covid-19 confinement, the use of electronic devices might have contributed 
TABLE 2 | Differences regarding health-related behaviors before and during Covid-19 confinement.

\begin{tabular}{|c|c|c|c|c|c|c|c|c|}
\hline & $n(\%)$ & $\begin{array}{c}\text { Before } \\
\text { confinement } \\
\text { Mean (SD) }\end{array}$ & $\begin{array}{c}\text { During } \\
\text { confinement } \\
\text { Mean (SD) }\end{array}$ & $\begin{array}{l}\text { Difference (before } \\
\text { and during } \\
\text { confinement) (SD) }\end{array}$ & $t$ & df & $p$-value ${ }^{a}$ & $d^{b}$ \\
\hline \multicolumn{9}{|l|}{ Physical Activity } \\
\hline \multicolumn{9}{|l|}{ (min/week) } \\
\hline Overall $(n=860)$ & & $198.6(180.9)$ & $96.1(123.0)$ & $-102.5(159.6)$ & 18.8 & 859 & 0.0000 & 0.66 \\
\hline \multicolumn{9}{|l|}{ Gender } \\
\hline Boys & $437(50.8)$ & $211.9(188.4)$ & 104.8 (130.0) & $-107.1(170.2)$ & 13.1 & 436 & 0.0000 & 0.66 \\
\hline Girls & $423(49.2)$ & $184.9(172.0)$ & $87.2(114.9)$ & $-97.7(148.0)$ & 13.6 & 422 & 0.0000 & 0.67 \\
\hline \multicolumn{9}{|l|}{ Age } \\
\hline$\geq 3$ and $\leq 5$ years & $162(18.8)$ & $223.0(198.0)$ & $131.0(160.2)$ & $-92.0(174.0)$ & 6.7 & 161 & 0.0000 & 0.51 \\
\hline$\geq 6$ and $\leq 12$ years & $459(53.4)$ & $209.0(180.0)$ & $88.6(112.4)$ & $-120.4(159.0)$ & 16.2 & 458 & 0.0000 & 0.80 \\
\hline$\geq 13$ and $\leq 16$ years & $239(27.8)$ & $162.1(165.3)$ & $86.9(109.3)$ & $-75.2(146.4)$ & 7.9 & 238 & 0.0000 & 0.54 \\
\hline \multicolumn{9}{|c|}{ Screen Exposure (h/day) } \\
\hline Overall $(n=860)$ & & $2.0(1.6)$ & $4.9(2.3)$ & $2.9(2.1)$ & 39.4 & 859 & 0.0000 & 1.43 \\
\hline \multicolumn{9}{|l|}{ Gender } \\
\hline Boys & $437(50.8)$ & $2.1(1.7)$ & $5.0(2.4)$ & $2.9(2.2)$ & 28.0 & 436 & 0.0000 & 1.43 \\
\hline Girls & $423(49.2)$ & $1.9(1.5)$ & $4.7(2.3)$ & $2.8(2.1)$ & 27.7 & 422 & 0.0000 & 1.44 \\
\hline \multicolumn{9}{|l|}{ Age } \\
\hline$\geq 3$ and $\leq 5$ years & $162(18.8)$ & $1.7(1.9)$ & $3.9(2.0)$ & $2.2(2.4)$ & 11.6 & 161 & 0.0000 & 1.13 \\
\hline$\geq 6$ and $\leq 12$ years & $459(53.4)$ & $1.9(1.5)$ & 4.7 (2.3) & $2.9(2.0)$ & 30.8 & 458 & 0.0000 & 1.46 \\
\hline$\geq 13$ and $\leq 16$ years & $239(27.8)$ & $2.4(1.3)$ & $5.8(2.3)$ & $3.3(2.1)$ & 24.7 & 238 & 0.0000 & 1.74 \\
\hline \multicolumn{9}{|l|}{ Sleep Time (h/day) } \\
\hline Overall $(n=860)$ & & $9.1(1.2)$ & $9.2(1.6)$ & $0.1(1.8)$ & 1.5 & 859 & 0.1288 & 0.06 \\
\hline \multicolumn{9}{|l|}{ Gender } \\
\hline Boys & $437(50.8)$ & $9.1(1.2)$ & $9.3(1.6)$ & $0.2(1.7)$ & 1.9 & 436 & 0.0648 & 0.11 \\
\hline Girls & $423(49.2)$ & $9.1(1.2)$ & $9.1(1.7)$ & $0.0(1.8)$ & 0.3 & 422 & 0.7635 & 0.02 \\
\hline \multicolumn{9}{|l|}{ Age } \\
\hline$\geq 3$ and $\leq 5$ years & $162(18.8)$ & $9.8(1.2)$ & $9.4(1.7)$ & $-0.4(1.8)$ & 3.1 & 161 & 0.0025 & 0.30 \\
\hline$\geq 6$ and $\leq 12$ years & $459(53.4)$ & $9.2(1.1)$ & $9.2(1.6)$ & $0.0(1.7)$ & 0.1 & 458 & 0.9563 & 0.00 \\
\hline$\geq 13$ and $\leq 16$ years & $239(27.8)$ & $8.5(1.0)$ & $9.1(1.7)$ & $0.6(1.7)$ & 5.4 & 238 & 0.0000 & 0.44 \\
\hline \multicolumn{9}{|l|}{ Fruit and Vegetable } \\
\hline \multicolumn{9}{|c|}{ Consumption (portion/day) } \\
\hline Overall $(n=860)$ & & $3.2(2.0)$ & $3.0(2.1)$ & $-0.2(1.6)$ & 3.4 & 859 & 0.0007 & 0.09 \\
\hline \multicolumn{9}{|l|}{ Gender } \\
\hline Boys & $437(50.8)$ & $3.3(2.1)$ & $3.1(2.2)$ & $-0.2(1.6)$ & 2.3 & 436 & 0.0213 & 0.08 \\
\hline Girls & $423(49.2)$ & $3.1(1.9)$ & $2.9(1.9)$ & $-0.2(1.6)$ & 2.5 & 422 & 0.0125 & 0.11 \\
\hline \multicolumn{9}{|l|}{ Age } \\
\hline$\geq 3$ and $\leq 5$ years & $162(18.8)$ & $3.7(2.1)$ & $3.1(2.1)$ & $-0.6(2.0)$ & 3.7 & 161 & 0.0003 & 0.28 \\
\hline$\geq 6$ and $\leq 12$ years & $459(53.4)$ & $3.1(2.0)$ & $2.9(2.0)$ & $-0.2(1.5)$ & 2.7 & 458 & 0.0064 & 0.10 \\
\hline$\geq 13$ and $\leq 16$ years & $239(27.8)$ & $3.0(2.0)$ & $3.1(2.1)$ & $0.1(1.4)$ & 1.1 & 238 & 0.2800 & 0.05 \\
\hline
\end{tabular}

a $t$-paired test (before and during confinement).

${ }^{b}$ Cohen's d: small 0.20; medium 0.50; large 0.80 .

to increasing children's behavior as regards exposure to screen since there is a possibility of children being influenced by their parent's behaviors regarding this issue; family environment concerning screen exposure has been observed to directly associate with children's exposure to screens (44). Further, the increase of hours exposed in front of a screen observed in this study might also explain the lower levels of physical activity found since higher screen time has been previously associated with lower physical activity among Spanish adolescents (12).

\section{Sleep Time}

Because children were experiencing a change as regards their usual daily habits, it was expected to find different sleep times in this study; overall, sleep time variations are normal among children aged between 3 and 7 years (45). However, contrary to expected, sleep time tended to slightly increase during the confinement, even though higher screen time and lower physical activity could have reduced sleep time since the opposite was observed in prior research with children $(46,47)$. However, 
TABLE 3 | Differences regarding health-related behaviors between strict and relaxed Covid-19 confinement.

\begin{tabular}{|c|c|c|c|c|c|c|c|c|}
\hline & $n(\%)$ & $\begin{array}{c}\text { Strict } \\
\text { confinement } \\
\text { Mean (SD) }\end{array}$ & $\begin{array}{c}\text { Relaxed } \\
\text { confinement } \\
\text { Mean (SD) }\end{array}$ & $\begin{array}{l}\text { Difference (strict } \\
\text { and relaxed } \\
\text { confinement) (SD) }\end{array}$ & $t$ & df & $p$-value ${ }^{a}$ & $d^{b}$ \\
\hline \multicolumn{9}{|l|}{ Physical Activity } \\
\hline \multicolumn{9}{|l|}{ (minutes/week) } \\
\hline Overall $(n=860)$ & & $95.5(123.8)$ & $97.8(121.4)$ & $2.3(9.3)$ & 0.2 & 858 & 0.8051 & 0.02 \\
\hline \multicolumn{9}{|l|}{ Gender } \\
\hline Boys & $437(50.8)$ & $103.8(130.0)$ & $107.4(130.6)$ & $3.6(13.7)$ & 0.2 & 435 & 0.7924 & 0.03 \\
\hline Girls & $423(49.2)$ & $86.9(116.7)$ & $87.9(110.8)$ & $1.0(12.3)$ & 0.1 & 421 & 0.9341 & 0.01 \\
\hline \multicolumn{9}{|l|}{ Age } \\
\hline$\geq 3$ and $\leq 5$ years & $162(18.8)$ & $119.8(148.0)$ & $156.2(183.7)$ & $36.4(27.2)$ & 1.3 & 160 & 0.1826 & 0.23 \\
\hline$\geq 6$ and $\leq 12$ years & $459(53.4)$ & $90.2(119.9)$ & $84.9(93.2)$ & $-5.3(11.4)$ & 0.5 & 457 & 0.6414 & 0.05 \\
\hline$\geq 13$ and $\leq 16$ years & $239(27.8)$ & $89.6(113.0)$ & 78.8 (99.5) & $-10.8(16.3)$ & 0.7 & 237 & 0.5098 & 0.10 \\
\hline \multicolumn{9}{|c|}{ Screen Exposure (h/day) } \\
\hline Overall & & $4.9(2.3)$ & $4.8(2.3)$ & $0.1(0.2)$ & 0.8 & 858 & 0.4345 & 0.06 \\
\hline \multicolumn{9}{|l|}{ Gender } \\
\hline Boys & $437(50.8)$ & $5.1(2.4)$ & $4.8(2.3)$ & $-0.3(0.2)$ & 1.2 & 435 & 0.2075 & 0.13 \\
\hline Girls & $423(49.2)$ & $4.7(2.3)$ & $4.7(2.4)$ & $0.0(0.2)$ & 0.2 & 421 & 0.8478 & 0.02 \\
\hline \multicolumn{9}{|l|}{ Age } \\
\hline$\geq 3$ and $\leq 5$ years & $162(18.8)$ & $4.0(1.9)$ & $3.9(2.2)$ & $-0.1(0.3)$ & 0.3 & 160 & 0.7290 & 0.06 \\
\hline$\geq 6$ and $\leq 12$ years & $459(53.4)$ & 4.7 (2.3) & $4.8(2.3)$ & $0.1(0.2)$ & 0.4 & 457 & 0.6543 & 0.05 \\
\hline$\geq 13$ and $\leq 16$ years & $239(27.8)$ & $5.9(2.3)$ & $5.4(2.4)$ & $-0.4(0.3)$ & 1.2 & 237 & 0.2315 & 0.18 \\
\hline \multicolumn{9}{|l|}{ Sleep Time (h/day) } \\
\hline Overall & & $9.3(1.6)$ & $9.0(1.7)$ & $-0.3(0.1)$ & 2.3 & 858 & 0.0209 & 0.17 \\
\hline \multicolumn{9}{|l|}{ Gender } \\
\hline Boys & $437(50.8)$ & $9.4(1.6)$ & $9.0(1.6)$ & $-0.4(0.2)$ & 2.2 & 435 & 0.0255 & 0.23 \\
\hline Girls & $423(49.2)$ & $9.2(1.6)$ & $9.0(1.8)$ & $-0.2(0.2)$ & 1.0 & 421 & 0.2956 & 0.11 \\
\hline \multicolumn{9}{|l|}{ Age } \\
\hline$\geq 3$ and $\leq 5$ years & $162(18.8)$ & $9.5(1.6)$ & $9.2(1.8)$ & $-0.3(0.3)$ & 0.9 & 160 & 0.3715 & 0.15 \\
\hline$\geq 6$ and $\leq 12$ years & $459(53.4)$ & $9.3(1.6)$ & $9.0(1.7)$ & $-0.3(0.2)$ & 2.1 & 457 & 0.0350 & 0.21 \\
\hline$\geq 13$ and $\leq 16$ years & $239(27.8)$ & $9.2(1.6)$ & $9.0(1.8)$ & $-0.2(0.2)$ & 0.8 & 237 & 0.4010 & 0.13 \\
\hline \multicolumn{9}{|l|}{ Fruit and Vegetable } \\
\hline \multicolumn{9}{|c|}{ Consumption (portion/day) } \\
\hline Overall & & $3.1(2.1)$ & $2.8(1.9)$ & $-0.2(0.2)$ & 1.6 & 858 & 0.1127 & 0.12 \\
\hline \multicolumn{9}{|l|}{ Gender } \\
\hline Boys & $437(50.8)$ & $3.2(2.3)$ & $2.9(1.9)$ & $-0.3(0.2)$ & 1.4 & 435 & 0.1554 & 0.15 \\
\hline Girls & $423(49.2)$ & $2.9(1.9)$ & $2.8(2.0)$ & $-0.2(0.2)$ & 0.8 & 421 & 0.4356 & 0.08 \\
\hline \multicolumn{9}{|l|}{ Age } \\
\hline$\geq 3$ and $\leq 5$ years & $162(18.8)$ & $3.2(2.0)$ & $3.1(2.4)$ & $-0.1(0.4)$ & 0.2 & 160 & 0.8463 & 0.03 \\
\hline$\geq 6$ and $\leq 12$ years & $459(53.4)$ & $3.0(2.1)$ & $2.7(1.8)$ & $-0.3(0.2)$ & 1.3 & 457 & 0.2073 & 0.13 \\
\hline$\geq 13$ and $\leq 16$ years & $239(27.8)$ & $3.2(2.2)$ & $2.8(1.9)$ & $-0.3(0.3)$ & 1.1 & 237 & 0.2828 & 0.16 \\
\hline
\end{tabular}

at-test between groups (strict and relaxed confinement).

${ }^{b}$ Cohen's d: small 0.20; medium 0.50; large 0.80 .

Bold values mean significant values $(p<0.05)$.

this increase was similar to what was found in another study among Italian children and adolescents during the Covid-19 confinement (30); thus, this situation might have contributed to reinforcing timetables, which, in turn, might have been useful to mitigate potential detrimental effects over adequate sleep time (48). In contrast, a recent study among French adults found that $47 \%$ reported a decrease in sleep quality during quarantine, with sleep reduction being the most associated factor (49).

\section{Fruit and Vegetable Consumption}

There is no prior evidence on how Covid-19 confinement might have influenced eating habits as regards fruits and vegetables among children and adolescents. Interestingly, our study found an important significant reduction of fruit and vegetable consumption during the Covid-19 confinement for the subgroup of children aged between 3 and 5 years. A possible explanation for this finding might be related to difficulties balancing family and working life since many parents have had to 


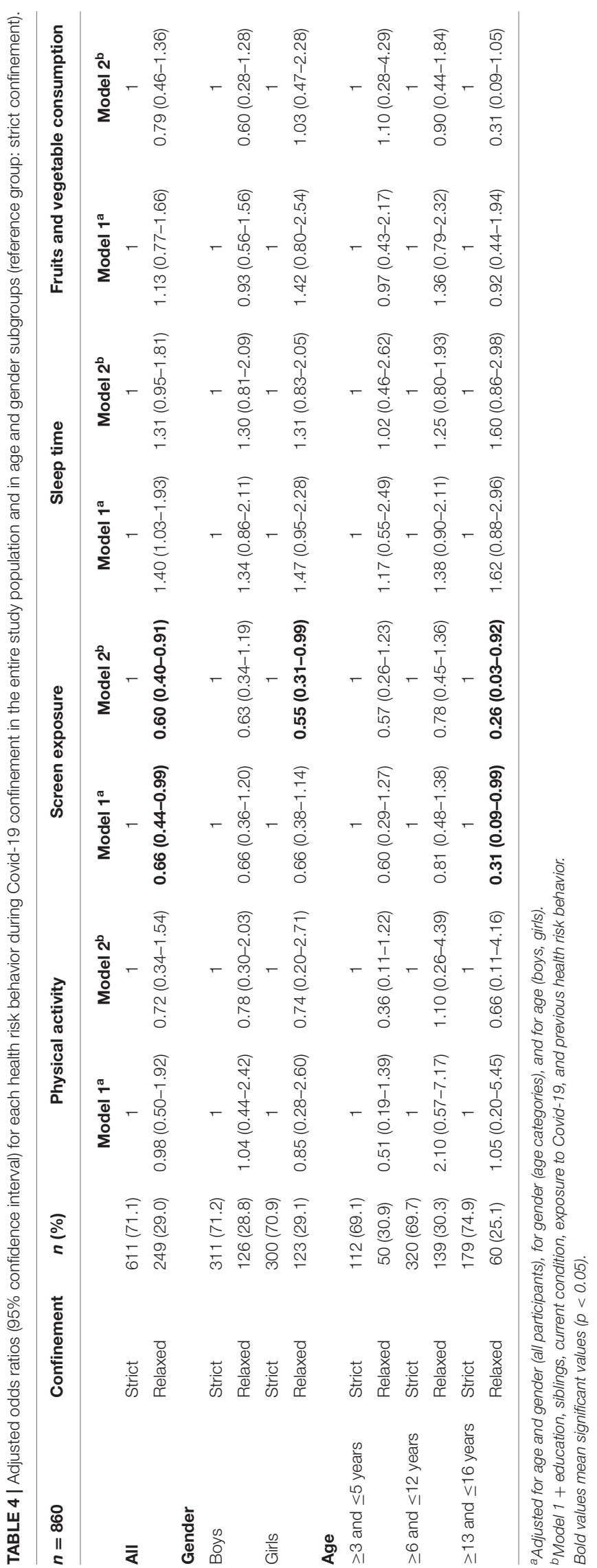

TABLE 5 | Differences between relaxed confinement and strict confinement for each health-related behavior.

\begin{tabular}{lcccc}
\hline Health-related behavior & \multicolumn{5}{c}{ ATT } \\
\cline { 2 - 5 } & Treated & Control & Difference (SD) & $\boldsymbol{p}$ \\
\hline Physical activity (min/week) & 97.8 & 90.0 & $7.8(9.5)$ & 0.393 \\
Screen exposure (h/day) & 4.8 & 4.9 & $-0.1(0.2)$ & 0.464 \\
Sleep time (h/day) & 9.0 & 9.1 & $-0.1(0.2)$ & 0.270 \\
Fruits and vegetable & 2.8 & 3.1 & $-0.3(0.2)$ & 0.105 \\
consumption (portion/day) & & & &
\end{tabular}

ATT, average treatment effect on treated calculated as a difference for each health-related behavior between the relaxed confinement (treated) and strict confinement (control); difference, treated-controls; SD, standard deviation.

telework while taking care of their children during the Covid-19 pandemic; this situation might have led to poorer eating habits, particularly among those children potentially less independent (i.e., younger children). Similarly, a study with Italian children and adolescents confined due to Covid-19 pandemic showed higher red meat, potato chip, and sugary drink consumption (30), which suggests that, as observed in the present study, eating habits overall might have worsened during the confinement. In contrast, a recent survey among 600 Spanish adults reported that most of the participants maintained vegetable and fruit consumption during the first 5 confinement weeks, although these results might have changed after the whole confinement period (50). Also, lower food away from home consumption was linked to changes in diet quality (i.e., less added sugars and added fats, and more fiber consumption) (51), although, for this specific and unprecedented context differences regarding usual eating habits and socioeconomic family status (i.e., higher family socioeconomic status usually lead to healthier eating habits), self-regulating behaviors and knowledge might play an important role (52). Also, school canteen deprivation could influence the fruit and vegetable consumption since that has observed to worsen healthy habits concerning diet (53). Besides, since the likelihood of eating at convenience during Covid-19 confinement might have increased, that could have contributed to maintaining similar levels of fruit and vegetable consumption during this period as the active choice could benefit this behavior among children (54).

Overall, both parental guidance and example can strongly influence children's and adolescent behaviors regarding diet, screen, and physical activity habits $(55,56)$, which, in turn, could be also influenced by socioeconomic variables such as education and income (i.e., higher education or higher income may lead to healthier HRB) $(52,57)$. Health complications for children and adolescents derived from prolonged confinement or repeated viruses' outbreaks might comprise a higher fat percentage, lower bone mineral density, lower motor competence, higher blood pressure, and higher socio-emotional behavior problems later, among others (58-63). Therefore, further research examining longitudinal consequences of confinement over objectively assessed health behaviors (e.g., use of accelerometers for estimating physical activity) would contribute to better understand the reasons for changes in 
HRBs as well as to define better strategies aimed at vulnerable populations such as children and adolescents; also, the study of adaptive patterns for HRBs as those observed for adults during the Covid-19 confinement could contribute to better understand the nature and severity of these changes (28).

\section{Strengths and Limitations}

Strengths of the current study consist of examining a large and well-disseminated sample of Spanish children and adolescents (i.e., participants from all the Spanish regions), and the analysis of an important set of control variables such as previous health conditions or exposure to Covid-19 in the referred time. Besides, the trends for specific HRBs such as physical activity or screen exposure remain consistent overall as well as in subgroup analyses. On the other hand, an important limitation of this study was self-reported data by parents, which may lead to recall bias; as suggested by Thorn et al. (64) outcomes such as physical activity, screen, and diet reported by children possibly lead to different estimations as regards their parents. Owing to their brevity, single-item questions have been recommended to apply in specific contexts of illness and frailty (65); thereby, the authors decided to use it in this specific context of confinement due to Covid-19 pandemic even though these specific questions were not specifically validated. Also, the convenience sampling method used to recruit participants might lead to a selection bias, which, in turn, could have shown a biased estimation of the study variables concerning the study population; thus, interpretation of the results of this study should be made in the light of this information. Further, the wide age range used for this study hampers generalizations on populations of children of a specific age. Last, the observational design of the study does not allow us to infer any causality.

\section{CONCLUSION}

The results found in the present study suggest that Covid-19 confinement substantially reduced physical activity levels,

\section{REFERENCES}

1. de España G. Real Decreto 463/2020, de 14 de marzo, por el que se declara el estado de alarma para la gestión de la situación de crisis sanitaria ocasionada por el COVID-19. (2020). Available online at: https://www.boe.es/buscar/doc. php?id=BOE-A-2020-3692 (accessed May 22, 2020).

2. de España G. Prórroga del estado de alarma; (2020). Available online at: https://www.lamoncloa.gob.es/consejodeministros/Paginas/enlaces/050520enlaceprorroga.aspx (accessed May 22, 2020).

3. Ong JSM, Tosoni A, Kim YJ, Kissoon N, Murthy S. Coronavirus disease 2019 in critically ill children: a narrative review of the literature. Pediatr Crit Care Med. (2020) 21:622-6. doi: 10.1097/PCC.0000000000002376

4. Di Lorenzo G, Di Trolio R. Coronavirus disease (COVID-19) in Italy : analysis of risk factors and proposed remedial measures. Front Med (Lausanne). (2020) 7:23-6. doi: 10.3389/fmed.2020.00140

5. Viner RM, Russell SJ, Croker H, Packer J, Ward J, Standsfield J, et al. School closure and management practices during coronavirus outbreaks including COVID-19 : a rapid systematic review. Lancet Child Adolesc Heal. (2020) 4:397-404. doi: 10.1016/S2352-4642(20)30095-X increased both screen exposure and sleep time, and reduced fruit and vegetable consumption; thus, most of HRBs worsen among a sample of Spanish children and adolescents. Also, the 1st weeks of confinement did not seem to significantly improve HRBs, except sleep time. Restrictive mobility measures with the closure of schools and high schools could have played an important role in this HRB worsening, which could be mitigated with policies for labor and family time conciliation, parental guidance, and community support.

\section{DATA AVAILABILITY STATEMENT}

The raw data supporting the conclusions of this article will be made available by the authors, without undue reservation.

\section{ETHICS STATEMENT}

The studies involving human participants were reviewed and approved by Ethics Committee of Research in Humans of the University of Valencia. Written informed consent to participate in this study was provided by the participants' legal guardian/next of kin.

\section{AUTHOR CONTRIBUTIONS}

RL-B, GL-S, AG-S, IG, LS, and JC contributed to the conception and design of the study. RL-B organized the database and wrote the first draft of the manuscript. RL-B and LS performed the statistical analysis. JC, AG-S, LS, IG, MT, and JAC wrote sections of the manuscript. All authors contributed to the article and approved the submitted version.

\section{ACKNOWLEDGMENTS}

The authors thank the participants for their contribution to the study.

6. World Health Organization (WHO). The Impact of COVID-19 on Children. Geneva. (2020). Avaliable online at: https://unsdg.un.org/sites/default/files/ 2020-04/160420_Covid_Children_Policy_Brief.pdf (accessed May 24, 2020).

7. Caspi A, Harrington HL, Moffitt TE, Milne BJ, Poulton R. Socially isolated children 20 years later: risk of cardiovascular disease. Arch Pediatr Adolesc Med. (2006) 8:805-11. doi: 10.1001/archpedi.160.8.805

8. Bick J, Luyster R, Fox NA, Zeanah CH, Nelson CA. Effects of early institutionalization on emotion processing in 12-year-old youth. Dev Psychopathol. (2017) 29:1749-61. doi: 10.1017/S0954579417001377

9. Levin AR, Zeanah CH, Fox NA, Nelson CA. Motor outcomes in children exposed to early psychosocial deprivation. J Pediatr. (2014) 164:123-9.e1. doi: 10.1016/j.jpeds.2013.09.026

10. Young A, Luyster RJ, Fox NA, Zeanah CH, Nelson CA. The effects of early institutionalization on emotional face processing: evidence for sparing via an experience-dependent mechanism. Br J Dev Psychol. (2017) 35:439-53. doi: 10.1111/bjdp.12185

11. Haycraft E, Sherar LB, Griffiths P, Biddle SJH, Pearson N. Screen-time during the after-school period: a contextual perspective. Prev Med Rep. (2020) 19:101116. doi: 10.1016/j.pmedr.2020.101116 
12. Serrano-Sanchez JA, Martí-Trujillo S, Lera-Navarro A, Dorado-García C, González-Henríquez JJ, Sanchís-Moysi J. Associations between screen time and physical activity among Spanish adolescents. PLoS ONE. (2011) 6:e24453. doi: 10.1371/journal.pone.0024453

13. Khan MKA, Chu YL, Kirk SFL, Veugelers PJ. Are sleep duration and sleep quality associated with diet quality, physical activity, and body weight status? a population-based study of Canadian children. Can J Public Heal. (2015) 106:e277-82. doi: 10.17269/CJPH.106.4892

14. Meira E, Cruz M, Miyazawa M, Gozal D. Putative contributions of circadian clock and sleep in the context of SARS-CoV-2 infection. Eur Respir J. (2020) 55:2001023. doi: 10.1183/13993003.01023-2020

15. Giustino V, Parroco AM, Gennaro A, Musumeci G, Palma A, Battaglia G. Physical activity levels and related energy expenditure during COVID-19 quarantine among the sicilian active population: a cross-sectional online survey study. Sustainability. (2020) 12:4356. doi: 10.3390/su12114356

16. López-Bueno R, Calatayud J, Andersen LL, Balsalobre-Fernández C, Casaña J, Casajús JA, et al. Immediate impact of the COVID-19 confinement on physical activity levels in Spanish adults. Sustainability. (2020) 12:5708. doi: $10.3390 /$ su12145708

17. Maugeri G, Castrogiovanni P, Battaglia G, Pippi R, D’Agata V, Palma A, et al. The impact of physical activity on psychological health during Covid-19 pandemic in Italy. Heliyon. (2020) 6:e04315. doi: 10.1016/j.heliyon.2020.e04315

18. López-Bueno R, Calatayud J, Ezzatvar Y, Casajús JA, Smith L, Tully MA, et al. Association between current physical activity and current perceived anxiety and mood in the initial phase of COVID-19 confinement. Front Psychiatry. (2020) 11:729. doi: 10.3389/fpsyt.2020.00729

19. von Elm E, Altman DG, Egger M, Pocock SJ, Gøtzsche PC, Vandenbroucke JP. The Strengthening the Reporting of Observational Studies in Epidemiology (STROBE) statement: guidelines for reporting observational studies. J Clin Epidemiol. (2008) 61:344-9. doi: 10.1016/j.jclinepi.2007.11.008

20. Milton K, Bull FC, Bauman A. Reliability and validity testing of a single-item physical activity measure. Br J Sports Med. (2011) 45:203-8. doi: 10.1136/bjsm.2009.068395

21. de Brito JN, Loth KA, Tate A, Berge JM. Associations between parent selfreported and accelerometer-measured physical activity and sedentary time in children: ecological momentary assessment study. JMIR Mhealth Uhealth. (2020) 8:e15458. doi: 10.2196/15458

22. WHO. Global Recommendations on Physical Activity for Health. Geneva. (2014). Avaliable online at: https://www.who.int/dietphysicalactivity/globalPA-recs-2010.pdf (accessed May 24, 2020).

23. Miller V, Mente A, Dehghan M, Rangarajan S, Zhang X, Swaminathan S, et al. Fruit, vegetable, and legume intake, and cardiovascular disease and deaths in 18 countries (PURE): a prospective cohort study. Lancet. (2017) 390:2037-49. doi: 10.1016/S0140-6736(17)32253-5

24. Paruthi S, Brooks LJ, D’Ambrosio C, Hall WA, Kotagal S, Lloyd RM, et al. Consensus statement of the American academy of sleep medicine on the recommended amount of sleep for healthy children: methodology and discussion. J Clin Sleep Med. (2016) 12:1549-61. doi: 10.5664/jcsm.6288

25. Barnett TA, Kelly CAS, Young DR, Perry CK, Pratt CA, Edwards NM, et al. Sedentary behaviors in today's youth: approaches to the prevention and management of childhood obesity a scientific statement from the American heart association. Circulation. (2018) 138:E142-59. doi: 10.1161/CIR.0000000000000591

26. McKenzie TL, Baquero B, Crespo NC, Arredondo EM, Campbell NR, Elder JP. Environmental correlates of physical activity in Mexican American children at home. J Phys Act Heal. (2008) 5:579-91. doi: 10.1123/jpah.5.4.579

27. Hnatiuk JA, Hesketh KR, Van Sluijs EMF. Correlates of home and neighbourhood-based physical activity in UK 3-4-year-old children. Eur J Public Health. (2016) 26:947-53. doi: 10.1093/eurpub/ckw067

28. López-Bueno R, Calatayud J, Casaña J, Casajús JA, Smith L, Tully MA, et al. COVID-19 confinement and health risk behaviors in Spain. Front Psychol. (2020) 11:1426. doi: 10.3389/fpsyg.2020.01426

29. Andersen KL, Seliger V, Rutenfranz J, Nesset T. Physical performance capacity of children in Norway. Eur J Appl Physiol Occup Physiol. (1980) 45:155-66. doi: $10.1007 /$ bf00421323

30. Pietrobelli A, Pecoraro L, Ferruzzi A, Heo M, Fayth M, Zoller T, et al. Effects of COVID-19 lockdown on lifestyle behaviors in children with obesity living in Verona, Italy: a longitudinal study. Obesity. (2020) 28:1382-5. doi: 10.1002/oby.22861

31. Wagner MO, Bös K, Jekauc D, Karger C, Mewes N, Oberger J, et al. Cohort profile: the motorik-modul longitudinal study: physical fitness and physical activity as determinants of health development in German children and adolescents. Int J Epidemiol. (2014) 43:1410-16. doi: 10.1093/ije/dyt098

32. Adank AM, Van Kann DHH, Hoeboer JJAA, de Vries SI, Kremers SPJ, Vos SB. Investigating motor competence in association with sedentary behavior and physical activity in 7-to 11-year-old children. Int J Environ Res Public Health. (2018) 15:2470. doi: 10.3390/ijerph15112470

33. Wilkie HJ, Standage M, Gillison FB, Cumming SP, Katzmarzyk PT. Correlates of intensity-specific physical activity in children aged 9-11 years: a multilevel analysis of UK data from the International study of childhood obesity, lifestyle and the environment. BMJ Open. (2018) 8:1-11. doi: 10.1136/bmjopen-2017-018373

34. Gu X, Keller MJ, Weiller-Abels KH, Zhang T. The roles of physical activity and sedentary behavior on Hispanic children's mental health: a motor skill perspective. Qual Life Res. (2018) 27:185-93. doi: 10.1007/s11136-017-1687-1

35. Grao-Cruces A, Segura-Jiménez V, Conde-Caveda J, García-Cervantes L, Martínez-Gómez D, Keating XD, et al. The role of school in helping children and adolescents reach the physical activity recommendations: the UP\&DOWN study. J Sch Health. (2019) 89:612-18. doi: 10.1111/josh.12785

36. Ridgers ND, Lamb KE, Timperio A, Brown H, Salmon J. Investigating children's short-term responses to imposed or restricted physical activity. $J$ Phys Act Heal. (2018) 15:239-46. doi: 10.1123/jpah.2017-0297

37. Ridgers ND, Timperio A, Cerin E, Salmon J. Compensation of physical activity and sedentary time in primary school children. Med Sci Sports Exerc. (2014) 46:1564-69. doi: 10.1249/MSS.0000000000000275

38. Aires L, Pratt M, Lobelo F, Santos RM, Santos MP, Mota J. Associations of cardiorespiratory fitness in children and adolescents with physical activity, active commuting to school, and screen time. J Phys Act Health. (2011) 8:S198-205. doi: 10.1123/jpah.8.s2.s198

39. Aparicio-Ugarriza R, Mielgo-Ayuso J, Ruiz E, Ávila JM, Aranceta-Bartrina J, Gil A, et al. Active commuting, physical activity, and sedentary behaviors in children and adolescents from spain: findings from the ANIBES study. Int $J$ Environ Res Public Health. (2020) 17:668. doi: 10.3390/ijerph17020668

40. Zenic N, Taiar R, Gilic B, Blazevic M, Maric D, Pojskic H, et al. Levels and changes of physical activity in adolescents during the COVID-19 pandemic: contextualizing Urban vs. rural living environment. Appl Sci. (2020) 10:3997. doi: 10.3390/app10113997

41. Sekulic D, Blazevic M, Gilic B, Kvesic I, Zenic N. Prospective analysis of levels and correlates of physical activity during COVID-19 pandemic and imposed rules of social distancing; gender specific study among adolescents from Southern Croatia. Sustainability. (2020) 12:4072. doi: 10.3390/su12104072

42. King DL, Delfabbro PH, Billieux J, Potenza MN. Problematic online gaming and the COVID-19 pandemic. J Behav Addict. (2020) 9:184-6. doi: 10.1556/2006.2020.00016

43. Kalogeraki S, Papadaki M. The impact of mobile use on teenagers' socialization. Int J Interdiscip Soc Sci Annu Rev. (2010) 5:121-34. doi: $10.18848 / 1833-1882 / \mathrm{cgp} / \mathrm{v} 05 \mathrm{i} 04 / 51690$

44. Verloigne M, Van Lippevelde W, Bere E, Manios Y, Kovács, É, Grillenberger $\mathrm{M}$, et al. Individual and family environmental correlates of television and computer time in 10- to 12-year-old European children: the ENERGYproject energy balance-related behaviors. BMC Public Health. (2015) 15:912. doi: 10.1186/s12889-015-2276-2

45. Taylor RW, Williams SM, Farmer VL, Taylor BJ. The stability of sleep patterns in children 3 to 7 years of age. J Pediatr. (2015) 166:697-702.e1. doi: 10.1016/j.jpeds.2014.11.014

46. Janssen X, Martin A, Hughes AR, Hill CM, Kotronoulas G, Hesketh KR. Associations of screen time, sedentary time and physical activity with sleep in under 5s: a systematic review and meta-analysis. Sleep Med Rev. (2020) 49:101226. doi: 10.1016/j.smrv.2019.101226

47. Belmon LS, van Stralen MM, Busch V, Hamsen IA, Chinapaw MJM What are the determinants of children's sleep behavior? a systematic review of longitudinal studies. Sleep Med Rev. (2019) 43:60-70. doi: 10.1016/j.smrv.2018.09.007

48. Ávila-garcía M, Femia-marzo P, Huertas-delgado FJ, Tercedor P. Bidirectional associations between objective physical activity and sleep patterns in 
spanish school children. Int J Environ Res Public Health. (2020) 17:710. doi: 10.3390/ijerph17030710

49. Hartley S, Colas des Francs C, Aussert F, Martinot C, Dagneaux S, Londe V, et al. Les effets de confinement SARS-CoV-2 sur le sommeil : enquête en ligne au cours de la quatrième semaine de confinement. Encephale. (2020) 46:S53-9. doi: 10.1016/j.encep.2020.05.003

50. Romeo-Arroyo E, Mora M, Vázquez-Araújo L. Consumer behavior in confinement times: food choice and cooking attitudes in Spain. Int J Gastron Food Sci. (2020) 21:100226. doi: 10.1016/j.ijgfs.2020. 100226

51. Altman M, Cahill Holland J, Lundeen D, Kolko RP, Stein RI, Saelens BE, et al. Reduction in food away from home is associated with improved child relative weight and body composition outcomes and this relation is mediated by changes in diet quality. J Acad Nutr Diet. (2015) 115:1400-7. doi: 10.1016/j.jand.2015.03.009

52. Pereira B, Rosário P, Silva C, Figueiredo G, Núñez JC, Magalhães P. The mediator and/or moderator role of complexity of knowledge about healthy eating and self-regulated behavior on the relation between family's income and children's obesity. Int J Environ Res Public Health. (2019) 16:4207. doi: 10.3390/ijerph16214207

53. Henjum S, Torheim LE, Chortatos A, Gebremariam MK, Terragni L, Gjertsen M. Consumption habits of school canteen and non-canteen users among norwegian young adolescents: a mixed method analysis. BMC Pediatr. (2018) 18:328. doi: 10.1186/s12887-018-1299-0

54. Hakim SM, Meissen G. Increasing consumption of fruits and vegetables in the school cafeteria: the influence of active choice. $J$ Health Care Poor Underserved. (2013) 24:145-57. doi: 10.1353/hpu. 2013.0109

55. Gebremariam MK, Henjum S, Terragni L, Torheim LE. Correlates of fruit, vegetable, soft drink, and snack intake among adolescents: the ESSENS study. Food Nutr Res. (2016) 60:32512. doi: 10.3402/fnr.v60.32512

56. Xu H, Wen LM, Rissel C. Associations of parental influences with physical activity and screen time among young children: a systematic review. J Obes. (2015) 2015:1-23. doi: 10.1155/2015/546925

57. Tandon P, Grow HM, Couch S, Glanz K, Sallis JK, Frank LD, et al. Physical and social home environment in relation to children's overall and homebased physical activity and sedentary time. Prev Med. (2014) 66:39-44. doi: 10.1016/j.ypmed.2014.05.019

58. Gaya AR, Silva P, Martins C, Gaya A, Ribeiro JC, Mota J. Association of leisure time physical activity and sports competition activities with high blood pressure levels: study carried out in a sample of portuguese children and adolescents. Child Care Health Dev. (2011) 37:329-34. doi: 10.1111/j.1365-2214.2010.01179.x

59. Cardadeiro G, Baptista F, Rosati N, Zymbal V, Janz KF, Sardinha LB. Influence of physical activity and skeleton geometry on bone mass at the proximal femur in 10- to 12-year-old children-a longitudinal study. Osteoporos Int. (2014) 25:2035-45. doi: 10.1007/s00198-014-2729-y

60. Robinson S, Daly RM, Ridgers ND, Salmon J. Screen-based behaviors of children and cardiovascular risk factors. J Pediatr. (2015) 167:1239-45. doi: 10.1016/j.jpeds.2015.08.067

61. Foweather L, Knowles Z, Ridgers ND, O’Dwyer MV, Foulkes JD, Stratton G. Fundamental movement skills in relation to weekday and weekend physical activity in preschool children. J Sci Med Sport. (2015) 18:691-96. doi: 10.1016/j.jsams.2014.09.014

62. McDermott JM, Troller-Renfree S, Vanderwert R, Nelson CA, Zeanah $\mathrm{CH}$, Fox NA. Psychosocial deprivation, executive functions and the emergence of socio-emotional behavior problems. Front Hum Neurosci. (2013) 7:1-11. doi: 10.3389/fnhum.2013.00167

63. Collings PJ, Wijndaele K, Corder K, Westgate K, Ridgway CL, Sharp SJ, et al. Objectively measured physical activity and longitudinal changes in adolescent body fatness: an observational cohort study. Pediatr Obes. (2016) 11:107-14. doi: 10.1111/ijpo.12031

64. Thorn JE, De Lellis N, Chandler JP, Boyd K. Parent and child self-reports of dietary behaviors, physical activity, and screen time. J Pediatr. (2013) 162:557-61. doi: 10.1016/j.jpeds.2012.08.031

65. Bowling A. Just one question: if one question works, why ask several? J Epidemiol Community Health. (2005) 59:342-5. doi: $10.1136 /$ jech.2004.021204

Conflict of Interest: The authors declare that the research was conducted in the absence of any commercial or financial relationships that could be construed as a potential conflict of interest.

Copyright (® 2020 López-Bueno, López-Sánchez, Casajús, Calatayud, Gil-Salmerón, Grabovac, Tully and Smith. This is an open-access article distributed under the terms of the Creative Commons Attribution License (CC BY). The use, distribution or reproduction in other forums is permitted, provided the original author(s) and the copyright owner(s) are credited and that the original publication in this journal is cited, in accordance with accepted academic practice. No use, distribution or reproduction is permitted which does not comply with these terms. 